Valentina Sokolovska, Aleksandar Tomašević

UDC 316.472.3

Filozofski fakultet Univerziteta u Novom Sadu

Originalan naučni rad

valentina.sokolovska25@gmail.com,apach.tomasevic@gmail.com

\title{
POZICIJA I ULOGA U ANALIZI SOCIJALNIH MREŽA ${ }^{1}$
}

Osnovni cilj rada je da predstavi model strukturne ekvivalencije i da ukaže na njegov značaj u istraživanju pozicija u uloga u analizi socijalnih mreža. Stoga se $u$ radu najpre ukazuje na probleme definisanja pozicija i uloga kako u sociologiji, tako i u teoriji socijalnih mreža. Nakon toga se daje kratak pregled najznačajnijih radova u kojima je ovaj metod razvijen. Autori ukazuju na stroge zahteve koje strukturna ekvivalencija postavlja kao uslov za izvođenje, te na njenu ograničenu upotrebu u istraživačkom radu. Zbog toga se predstavljaju pojedini alternativni pristupi istraživanju pozicija i uloga.

Ključne reči: pozicija, uloga, metod strukturne ekvivalencije.

Pojmovi društvenog položaja i uloge veoma su dugo predmet pažnje i interesovanja brojnih naučnika. Prva ozbiljnija upotreba ovih pojmova potekla je iz antropologije u radu Lintona (Linton, 1936), da bi ih kasnije preuzeli sociolozi i socijalni psiholozi. Kako među ovim naučnicima postoji dosta neslaganja oko određivanja pojma društvenog položaja i uloga, proizašle su i veoma raznovrsne definicije datih pojmova. Tako se u sociologiji pojam društvenog položaja (statusa) upotrebljava u najmanje tri različita značenja: jedno je preuzeto od Lintona (Linton, 1936), u drugom se, koje razvija Veber (Veber, 1976) status poistovećuje sa ugledom, dok se u trećem pravi paralela sa životnim stilom, kao što to, u svojim radovima, čini Burdije (Burdije, 1998).

Sasvim je očekivano da se ova terminološka neusaglašenost oslikava i u teoriji socijalnih mreža. Tako Vaserman i Faust (Wassermen \& Faust, 1994) konstatuju da je njihova definicija pozicije najbliža Lintonovoj. U teoriji socijalnih mreža, s jedne strane, isti položaj zauzimaju pojedinci koji obavljaju slične društvene aktivnosti i

1 Ovaj rad nastao je kao rezultat rada na projektu „Značaj participacije u društvenim mrežama za prilagođavanje evrointegracijskim procesima“ podržan od strane Ministarstva za obrazovanje i nauku Republike Srbije. 
imaju slične veze ili interakcije, dok, na drugoj strani, uloge predstavljaju obrasce društvenih odnosa koji se uspostavljaju između aktera, tj. između pozicija. Dok za Vasermana pozicija predstavlja zbir ekvivalentnih aktera, Vajt i saradnici je definišu kao „svaki skup u kojem je populacija podeljena” (White et al. 1976: 769). Ovakav teorijski koncept jasno razdvaja pojam pozicije od grupne kohezije, jer pojedinci koji zauzimaju istu poziciju ne moraju biti u direktnoj ili indirektnoj vezi jedni sa drugima. Kako neki autori primećuju, termin pozicija pre svega podrazumeva konkurentni odnos a ne kohezioni (Knoke \& Yang, 2008: 76). Nadalje, uloga aktera u mreži podrazumeva asocijacije između relacija koje povezuju društvene pozicije. Ali, one nisu samo to: osim što ukazuje na vezu između dve pozicije, uloga podrazumeva i način na koji su ti odnosi povezani u celoj grupi aktera koji čine jednu mrežu. Zbog toga se one mogu analizirati na tri nivoa: pojedinačnom (na nivou aktera), grupnom (ukoliko je jedna socijalna mreža sastavljena od više grupa) i u celosti (na nivou mreže kao celine).

U analizi socijalnih mreža pojmovi položaja i uloge zauzimaju važno mesto. Otuda su - radi opisivanja strukture mreže - razvijeni metodi koji se bave identifikovanjem položaja i uloge koji akteri u njoj zauzimaju. Međutim, iako su svi oni u matematičkom smislu raznovrsni, imaju zajednički cilj, a to je predstavljanje složenih podataka na jednostavniji način i to formiranjem podskupova. Elementi ovako izdvojenih podskupova su akteri koji su na sličan način ugrađeni u odnose unutar mreže.

U razvoju mrežnih modela razlika između sličnosti i blizine se pokazala veoma korisnom. Za razliku od pozicionog pristupa relacionih podataka, koji počiva na sličnosti među akterima, relacioni pristupi se fokusiraju na blizini aktera geografskoj, fizičkoj ili društvenoj. Zbog toga je cilj pozicione analize podela aktera u međusobno isključive klase na osnovu principa sličnosti, dok relacioni pristup, razvijen iz tradicionalne sociometrije, pokušava da pronađe podskupove aktera koji su snažno povezani jedni sa drugima na osnovu principa kohezije ili blizine.

\section{POZICIONA ANALIZA NA OSNOVU STRUKTURNE EKVIVALENTNOSTI}

Jedan od najčešće korišćenih pristupa pozicione analize na osnovu strukturne ekvivalentnosti zaasnovan je na korelaciji i razvijen je od strane Vajta i njegovih 
saradnika (Lorrain \& White, 1971), dok drugi zastupa Bart (Burt 1976), koji koristi Euklidovu distancu kao alternativu za merenje strukturne ekvivalentnosti.

Međutim, prvo istraživanje uloga i pozicija u socijalnim mrežama nastalo je u antropologiji (White 1963), ali upotreba formalnih uloga i pozicione analize za otkrivanje socijalnih mreža sa složenijim varijetetima u odnosima počinje početkom 70-ih godina prošlog veka sa objavljivanjem rada Lorena i Vajta (Lorrain \& White, 1971). Njihov pristup analizi socijalnih mreža se razlikuje od drugih teorijskometodoloških pristupa toga vremena koji su se uglavnom oslanjali na teoriju grafova, jer su koristili apstraktni algebarski pristup proistekao iz matematičke teorije kategorija i grupa.

Uloga individue se u društvenom sistemu, u teoriji socijalnih mreža, često opisuje kao skup relacija različitih tipova koje povezuju tu osobu sa skupovima relacija drugih. Zbog toga Loren i Vajt predstavljaju individue kao čvorove koji se ne razlikuju po intrinzičnim atributima, kao što je pol na primer, a ukoliko između tih čvorova postoji veza, onda se može govoriti o postojanju relacije uloge. Dakle, ukupna suma uloga biće skup koji će se sastojati od veza različitog tipa, a ne od struktura višeg reda.

Preko prostih i višestrukih složenih relacija, Loren i Vajt dolaze do koncepta kategorije, koji je izuzetno važan jer se njime može opisati celokupna mreža u kojoj se svi objekti uzimaju istovremeno u razmatranje, dok teorija grafova razmatra samo određene cikluse i putanje koje spajaju određene čvorove. Redukcija kategorije predstavlja određenu projekciju te kategorije, prilikom koje se izostavljaju određeni aspekti njene strukture, a drugi se zadržavaju. Veliki broj takvih redukcija je moguć i autori ističu da se gotovo ništa ne može raditi sa kategorijama van konteksta njihovih redukcija i preklapanja tih redukcija, što je od posebne važnosti za sociološki pristup mrežama (Lorrain \& White, 1971: 15). Redukcijom čitave klase čvorova postaju strukturalno ekvivalentne i mogu se posmatrati kao zasebne jedinice. Iako je sama mreža podložna različitim promenama tokom vremena, određene redukcije mogu otkriti postojanje latentnih makrostruktura unutar same mreže, dok se druge mogu promeniti.

Vajt i Loren predviđaju da će „mreže postati značajne za sociologiju kao što su to Euklidski prostor i njegove generalizacije za fiziku" (Lorrain \& White, 1971: 33). U trenutku kada je ovaj rad objavljen, čak je i matematička teorija mreža bila 
na niskom stupnju razvoja. Teorija grafova je takođe imala nizak stupanj unutrašnje kohezije i nije pružala odgovore na pitanje odnosa između različitih relacija, kao ni jasno definisane kriterijume redukcije i poređenja grafova. Glavna snaga i prednost njihovog pristupa je mogućnost lociranja skupa individua koje zauzimaju slične pozicije u odnosu na sve druge skupove u individua, bez obzira kolika je njihova udaljenost unutar celokupne mreže.

Sejler (Sailer 1978) zastupa ideju da je u istraživanju strukturalne ekvivalencije od suštinskog značaja relacija ljudskih interakcija, odnosno da je međusobni odnos obrazaca različitih (socijalnih, ekonomskih) veza značajniji i interesantniji od odnosa dve određene grupe individua. Ovaj autor posmatra društvenu strukturu kao mrežu stvarno postojećih društvenih relacija, pri čemu ističe da društvena relacija ne predstavlja vezu između određenih osoba, već skup veza unutar celokupne populacije. Mreža predstavlja obrazac društvenih relacija, koje su definisane nad skupom osoba, pozicija, grupa ili organizacija. Samim tim individua postaje značajna kao pokretač ovakve ekstenzivne definicije relacija i Sejler smatra da individue ne čine društvenu strukturu, ali sama interakcija između njih može biti strukturirana.

Prema ovakvom stanovištu, određeni akteri unutar mreže postaju tranzitorni, odnosno oni mogu menjati svoje uloge (i pozicije) tokom vremena, a da društvena struktura ostaje ista. Kada pokušavamo da utvrdimo postojanje strukturalne ekvivalencije unutar određene mreže, mi zapravo tragamo za tranzitornim akterima unutar konkretne socijalne mreže (Sailer, 1978: 74).

Kao i Vajt, Sejler koristi tehnički (odnosno matematički) termin relacije, ali ističe da bi on u sociološkom smislu predstavljao ulogu. Ovaj autor definiše ulogu kao skup prikladnih ponašanja dva aktera unutar određenog konteksta i naglašava njeno dvostruko značenje. Uloga se može shvatiti kao kolektivni termin koji služi za opis određenih individualnih (ili mrežnih) atributa, ali i kao funkciju koju izvršava određena individua. Ipak, ono što je najznačajnije za koncept uloge je naglašavanje veza određene individue sa drugim individuama koje zauzimaju određene pozicije unutar mreže. U slučaju kada dvoje individua, koje imaju istu ulogu (odnosno nad njima je definisana ista relacija), mogu zameniti mesta unutar mreže, može se govoriti o strukturalnoj ekvivalenciji (Sailer, 1978: 74-75).

Na razvoj strukturne ekvivalencije u značajnoj meri uticao je još jedan rad koji će pokrenuti razvoj savremenijih, ali i alternativnijih oblika ovog metoda. 
Godine 1976. Bart objavljuje rad Pozicija u mrežama sa idejom da precizira skup odnosa do i od svakog aktera u sistemu. Meru u kojoj dva aktera zajedno zauzimaju isti položaj u mreži Bart posmatra kao socijalnu distancu između njih, a izražava je kao skalarnu vrednost. Međutim, osim što, za razliku od Lorena i Vajta, Bart (1976) socijalnu distancu definiše preko sociometrijskih veza, ovaj autor pravi razliku između jake i slabe strukturne ekvivalentnosti (Burt, 1976: 96). Dva aktera zauzimaju istu poziciju u mreži, odnosno strukturalno ekvivalentne pozicije, kada imaju iste odnose ka svakom akteru i od svakog aktera u mreži. Zahtev da svaki element bude identičan ako su akteri strukturno ekvivalentni predstavlja osnovni uslov jake strukturne ekvivalentnosti. Bart upozorava da ukoliko je reč o aktuelnim mrežnim relacijama jaka definicija ekvivalentnosti ima malu korist, jer će se verovatno pojaviti razlike između strukturalno ekvivalentnih pozicija zbog greške uzorkovanja, greške opservacija i/ili razlika između aktera. Zbog toga je za primenjena istraživanja korisnija slaba definicija ekvivalentnosti. Ona zahteva da socijalna distance između dva aktera bude manja od distanci između strukturno neekvivalentnih pozicija.

Uzimajući u obzir Vajtov i Bartov način definisanja strukturne ekvivalencije Vaserman i Faust (Wasserman \& Faust, 1994) upozoravaju da je potrebno voditi računa o tome kako se određena definicija može primeniti na različite tipove relacija, koje se mogu identifikovati u konkretnoj socijalnoj mreži. Pre svega, mora se utvrditi da li se mrežni podaci sastoje iz jedne ili više vrsta relacija. Potom, za svaku relaciju treba videti da li je dihotomna ili vrednosna, usmerena ili neusmerena, kao i relaciju u kojoj je veza elementa sa samim sobom supstantivno značajna (Wasserman \& Faust, 1994: 359).

Strukturalna ekvivalencija se lako definiše za dihotomne relacije objašnjavaju Veserman i Faust (Wasserman \& Faust, 1994, vid. i Knoke \& Yang, 2008), pošto veza između dva aktera ili postoji ili ne postoji. Ipak, kada relacije poseduju određenu „težinu”, odnosno vrednost, pitanje strukturalne ekvivalencije postaje komplikovanije, naročito ukoliko se ne utvrđuje samo njeno postojanje već se određuje stepen u kojem se odnos dva aktera približava savršenoj strukturalnoj ekvivalenciji.

Sprovođenje analize pozicija i uloga obično se vrši na složenim odnosima, objašnjava Kristina Prel (Prell, 2012). U dodeljivanju pozicija akterima potrebno je najpre izabrati definiciju ekvivalencije koja zadovoljava zahteve istraživača i 
odgovarajuće sredstvo za njeno merenje. Drugi korak je merenje ekvivalencije, a treći dodeljivanje pozicija akterima na osnovu izabrane definicije ekvivalencije i to pomoću blok matrica, hijerarhijskih klastera ili multidimenzionalnog skaliranja. Naredni se odnosi na formulisanje pojednostavljenih slika relacija između pozicija i na kraju dolazi interpretacija (Prell, 2012: 174-175).

\section{ALTERNATIVNI PRISTUPI ZA IDENTIFIKACIJU ULOGA I POZICIJA}

Uslov da strukturno ekvivalentni akteri moraju imati identične modele veza sa drugima je suviše strog i zbog toga malo upotrebljiv u praktične svrhe. Mada Bartova ideja o labavljenju kriterijuma i prihvatanje relacione sličnosti proširuje upotrebljivost i dalje se nameću veoma restriktivni uslovi za izvođenje ovog metoda. Zato su istraživači mreža, kao alternativu, razvili nekoliko manje restriktivnih pristupa za identifikaciju uloga i pozicija. Tako, na primer, Katarina Faust uvodi pojam opšte ekvivalencije podvodeći pod njega mnoge alternativne pristupe - ulogu lokalne ekvivalencije, ego-algebre i regularne ekvivalencije (Faust, 1988: 326).

Ovi pristupi zahtevaju drugačiji način razmišljanja i različite načine merenja sličnosti. Dok je zadatak strukturne ekvivalencije da se pronađu grupe sličnih pojedinaca na osnovu stepena u kome oni dele identične veze sa identičnim drugima, opšta ekvivalencija pronalazi grupe sličnih pojedinaca na osnovu razmene „tipova veza” sa „tipovima” drugih. Zbog toga oni identifikuju različite vrste društvenih grupa. Grupe nastale procedurom strukturne ekvivalentnosti imaju tendenciju da uključuju pojedince koji su tesno međusobno povezani ili sa istim drugima. Ova procedura je pogodan osnov za analizu ako je cilj otkrivanje društvenih pozicija. $\mathrm{S}$ druge strane, grupe nastale procedurama opšte ekvivalencije tačno odražavaju društvene tipove na primeru konstruisanom sa jasnom pozicionom strukturom i pronalaze grupe pojedinaca sa karakterističnom relacionom konfiguracijom (Faust, 1988: 338). Možemo zaključiti da strukturna metoda i metoda opšte ekvivalencije proizvode drugačije strukturne socijalne efekte. Zato je važan zadatak, smatra ova autorka (Faust, 1988: 339), da se istraže jasne posledice tih efekata i situacije u kojima ovi pristupi daju suprotna teorijska predviđanja.

Borgati i Everet (Borgatti \& Everett, 1992) idu korak dalje i prave razliku između strukturnih i apstraktnijih oblika ekvivalencije. Oni objašnjavaju (Borgatti \& 
Everett, 1992: 31) da dok strukturna ekvivalencija definiše poziciju na način „koga akter poznaje”, strukturni izomorfizam je određuje u smislu „načina na koji su akteri povezani”. Tako su strukturno ekvivalentni akteri najbliži i slični, dok su strukturni izomorfi samo slični. Nadalje, iako koheziono relacioni i strukturno ekvivalentni pristupi socijalne homogenosti ne zahtevaju da se postave različiti uzročni mehanizmi, u slučaju kohezionih i strukturnih izomorfa je to neophodno.

Iako su izomorfne i automorfne ekvivalencije bliski koncepti u tolikoj meri da ih izvesni analitičari smatraju zamenljivim (Borgatti \& Everett, 1992), između njih postoje i izvesne razlike. Prvo, izomorfne ekvivalencije se primenjuju na dva grafikona, dok automorfne ekvivalencije opisuju relacione karakteristike aktera u okviru jednog grafikona. Na taj način dva grafikona ukazuju na strukturalni izomorfizam, ukoliko mapiranje čvorova sa jednog grafikona na drugi nastoji da očuva sve međusobne odnose i povezanost čvorova (tj. isti ulazni i izlazni nivo). Drugim rečima, ako su dva čvora povezana na prvom grafikonu, tada odgovarajuća dva čvora na drugom grafikonu moraju biti povezana na isti način (Borgatti \& Everett, 1992: 11). Svaki grafikon je izomorfan sa samim sobom i to Borgati i Everet nazivaju automorfizam. Tako su dva učesnika automorfno ekvivalentni (združeno zauzimaju istu poziciju /isti položaj/) ako i samo ako su povezani sa drugim odgovarajućim pozicijama, ali ne i sa identičnim čvorovima. Automorfni ekvivalentni čvorovi imaju identična grafikonska teorijska svojstva, poput centralnosti, ego gustine i veličine klike, obajšnjavaju dalje ovi autori (Borgatti \& Everett, 1992).

Time automorfna ekvivalencija ublažava zahteve strukturne ekvivalencije da učesnici na istoj poziciji imaju identične ili veoma slične veze sa istom garniturom drugih učesnika. Umesto toga, automorfna ekvivalencija identifikuje učesnike koji zajedno zauzimaju istu poziciju ukoliko imaju identične veze sa različitim grupama učesnika. Na primer, da bi dva profesora zauzimala strukturalno ekvivalentnu poziciju i jedan i drugi bi morali da podučavaju istovetnu grupu učenika, što zapravo nije moguće. Ipak, da bi se zauzela automatski ekvivalentna pozicija, dva profesora bi trebalo da podučavaju samo različite grupe koje okupljaju isti broj učenika. Učenici zauzimaju drugu poziciju, a definisani su kao osobe koje su podučavane od strane profesorske pozicijeStrukturno ekvivalentni učesnici su takođe automorfno ekvivalentni, što ne znači da je i obrnut slučaj.

Regularna ekvivalencija je najmanje restriktivna forma ekvivalencije. Kao 
takva ona ne zahteva ni veze strukturne ekvivalencije sa identičnim učesnicima, niti pozicije automorfne ekvivalencije koje se ne mogu razlikovati. Akteri su regularno ekvivalentni ukoliko imaju istu vrstu odnosa sa akterima koji su takođe regularno ekvivalentni. Postoji još jedan način konceptualizacije ove ideje. Ukoliko je prvi učesnik koji zauzima određenu poziciju povezan sa nekim na drugoj poziciji, tada drugi učesnik koji je regularni ekvivalent mora imati identičnu vezu sa nekim drugim na drugoj poziciji (White \& Reitz, 1983: 214). Sve majke sa decom su regularni ekvivalenti, bez obzira na broj članova potomstva, kao što su i sva deca koja imaju majke. U bolnici, lekari su regularni ekvivalenti u odnosu na svoje pacijente i medicinsko osoblje, čak i kada broj pacijenata i medicinskog osoblja varira od lekara do lekara. Opštost regularne ekvivalence je čini možda i najvažnijom merom za sociologe koji nastoje da prikažu socijalne uloge i pozicije. I automorfna ekvivalencija i regularna ekvivalencija zahtevaju da se par učesnika povezuje sa drugim učesnicima koji su strukturno ekvivalentni na istoj relaciji. Međutim, razlika između automorfne i regularne ekvivalencije je ponekad dvosmislena. Automorfna ekvivalencija zahteva da grafikoni budu strogo zamenljivi (supstitutivni) jedan sa drugim, dok regularna ekvivalencija ne zahteva potpunu zamenljivost među podgrafikonima.

Dorejn, Bagatelj i Ferligoj (Doreian et al. 1994/2008) pokušavaju iznova da razmotre ideju ekvivalencije i predlažu nove načine pomoću kojih se određuju particije socijalne mreže, kao i metod za merenje adekvatnosti tih particija. Napomenimo da je njihov pristup socijalnim mrežama takođe algebarski i da se oslanja na teoriju skupova. Kada govore o samom pojmu ekvivalencije, ističu da se u praksi koriste najčešće dva oblika: strukturna i generalizovana ekvivalencija, koje i formalno definišu, ali napominju da se u literaturi o socijalnim mrežama mogu naći i drugi oblici ekvivalencije. Generalizovana ekvivalencija uzima u obzir jedino veze dva čvora mreže sa ostalim čvorovima. Ukoliko su oni povezani na isti način sa drugim čvorovima mreže onda se može govoriti o njihovoj generalizovanoj ekvivalenciji. Sa druge strane, pomoću strukturne ekvivalencije posmatraju se u strukturi kada dva elementa zamene svoje pozicije.

Možemo primetiti da Dorejn i saradnici, za razliku od Lorena i Vajta (Lorrain \& White, 1971), ne uvode pojmove kategorije i grupe kao nužne za definisanje strukturne ekvivalencije. Samim tim, njihova definicija postaje jednostavnija jer se sastoji iz pojmova koji su bliži konvencionalnim definicijama mreže. Loren i 
Vajt govore o redukcijama, odnosno o preslikavanju, dok se u ovom slučaju radi o automorfizmima, odnosno o permutacijama. Razlika je u tome što preslikavanje (redukcija) podrazumeva stvaranje nove kategorije, dok se kod automorfizma radi o promenama unutar samog skupa, pri čemu se ne zahteva da se analitički definiše i razmatra neki novi skup. Ova razlika dobija na značaju kada se analizira mreža sa velikim brojem jedinica, gde definisanje nove kategorije prilikom svake redukcije može biti naporno i kontraproduktivno, čak i ukoliko se analiza vrši pomoću računarskog programa. Automorfizam, u ovom slučaju, predstavlja permutaciju (zamenu mesta jedinica unutar mreže) koja ne menja osnovnu strukturu mreže. Ukoliko posmatramo samo jedan tip relacije unutar mreže, može se reći da nakon permutacije matrica relacija ostaje nepromenjena. Samim tim se dolazi do relativno jednostavne definicije strukturne ekvivalencije: dva elementa su strukturno ekvivalentna unutar jedne mreže, ukoliko se struktura mreže ne menja kada ta dva elementa zamena svoje pozicije unutar nje.

Autori ističu da prilikom konkretne analize izbor definicije, odnosno tipa ekvivalencije utiče na dalji tok analize, naročito ukoliko se radi o blok modelovanju, gde postoji direktna veza između tipa ekvivalencije i tipa blokova do kojih će se doći modelovanjem.

\section{ZNAČAJ STRUKTURNE EKVIVALENCIJE}

Iako je klasična strukturna ekvivalencija postavila stroge matematičke zahteve pred istraživače socijalnih mreža, ona je u velikoj meri doprinela rasvetljavanju pozicija i uloga koje pojedinci, grupe, pa i mreže u celini, zauzimaju u odnosima koje uspostavljaju jedni sa drugima. Popularnost ovog metoda ogleda se u njegovom razvijanju i prilagođavanju društvenim pojavama za čije istraživanje se često ne mogu primeniti metode prirodnih nauka. Istraživanja i njihovi rezultati na ovu temu su mnogobrojna i raznovrsna. Ovom prilikom navešćemo samo neka od njih. Istraživači su metod strukturne ekvivalencije koristili u etnografiji (Lane, 1962), medicini (Burt, 1987), političkoj sociologiji (Mizruchi, 1990), psihologiji (Kalish \& Robins, 2006) itd.

Strukturna ekvivalencija je korišćena i u istraživanjima organizacionih nauka. U radu u kojem proučavaju uticaj socijalnog kapitala i strukturnih rupa na 
nastanak mreže biotehnoloških firmi, Voker i saradnici (Walker et al. 1997) koriste koncept strukturne ekvivalencije kako bi bolje istražili istoriju razvoja ovog tipa mreže. Naime, oni tvrde da industrijske firme iznova stvaraju stabilan tip mrežne stukture, čije osnove su nastale u ranoj fazi razvoja te industrije. Samim tim, izbor kooperanata koje firme naprave ubrzo nakon svog osnivanja imaće značajan uticaj na tok kooperacije u budućnosti. Da bi potvrdili svoju tezu, oni analiziraju i porede mrežne strukture biotehnoloških firmi u periodu od 1984. do 1989. godine i pri tome posmatraju promene u strukturnoj ekvivalenciji tokom vremena, kako bi utvrdili koliko se mrežna struktura menja kako mreža tokom vremena sve više raste. Rezultati istraživanja pokazali su da ukoliko je par firmi strukturno ekvivalentan u ranoj fazi razvoja mreže, postoji visoka verovatnoća se tokom vremena to neće promeniti, a isto važi i za parove koji nisu ekvivalentni. (Walker et al. 1997: 120-121).

U analizi socijalnih mreža proučavanje saradnje među naučnicima je veoma raširena oblast istraživanja. Jedno od njih sproveo je i Patrik Doreian (Doreian, 1988). On je analizirao mreže citiranosti između 22 različita geografska časopisa, pri čemu je želeo da testira hipotezu o strukturnoj ekvivalenciji unutar ovakvog tipa mreže. Autor tvrdi da ukoliko dva časopisa bivaju citirana po identičnom obrascu unutar mreže, za njih se može reći da su strukturno ekvivalentna. Ipak, pošto je ovakav slučaj idealan, jer se u stvarnosti teško mogu identifikovati identični obrasci citiranja, uvodi se mera sličnosti obrazaca, koja određuje stepen u kome su dva časopisa u mreži bliski strukturnoj ekvivalenciji. (Doreian, 1988, 79-80)

Na kraju, prikazaćemo ukratko rad Palotija i Lomija (Palloti \& Lomi, 2011). Ova su dvojica autora sprovela istraživanje u kojem su ispitivali uticaj snage mrežnih veza i strukturne ekvivalencije na učinak aktera unutar mreže. Tačnije, oni su problem učinka posmatrali iz dve perspektive. Prva je relaciona (snaga veze) i zasnovana je na konceptu snage kontakta između čvorova mreže (u ovom slučaju organizacija), pri čemu veze unutar mreže predstavljaju tokove prenosa informacija, znanja, organizacionih praksi i materijalnih resursa. Druga perspektiva je poziciona i zasnovana je na Vajtovom konceptu strukturne ekvivalencije, pri čemu strukturno ekvivalentne organizacije zavise od istih resursa (ili od resursa koje kontrolišu isti izvori). Autori su analizirali regionalnu mrežu bolnica u centralnoj Italiji, pri čemu su veze između bolnica definisane brojem transfera pacijenata iz jedne u drugu. (Palloti \& Lomi, 2011: 389-390) Nakon analize rezultata istraživanja, autori zaključuju, 
između ostalog, i da će se organizacije, koje se nalaze na sličnim strukturnim pozicijama unutar inter-organizacione mreže u kojoj su ukorenjene, odnosno strukturno ekvivalentne organizacije, na sličan način ponašati, pa samim tim imati i sličan učinak u situacijama u kojima dele zajedničke resurse (Palloti \& Lomi, 2011: 400).

\section{LITERATURA}

Borgatti, P. Stephen and Martin G. Everett (1992). Nations of Position in Social Network Analysis. Sociological Methodology. 22: 1-35.

Burdije, Pjer (1998). Društveni prostor i simbolička moć. U: Spasić, Ivana (ur.) Interpretativna sociologija. Beograd: Zavod za udžbenike i nastavna sredstva, str. 143-158.

Burt, S. Ronald (1976). Position in Networks. Social Forces. 55/1: 93-122.

Burt, S. Ronald (1987). Social Contagion and Innovation: Cohesion versus Structural Equivalence. American Journal of Sociology. 92/6: 1287-1335.

Doreian, P. (1988) Testing structural-equivalence hypotheses in a network of geographical journals. Journal of the American Society for Information Science 39 (2): 79-85.

Doreian, P., V. Bagatelj and A. Ferligoj (1994/2008). Partitioning networks bases on generalized concepts of equivalence. In: L. C. Freeman (ed). Social Network Analysis Volume 3. The Structure of Social Positions. London: Sage Publications, pp. 211-238.

Faust, Katherine (1988). Comparison of methods for positional analysis: structural and general equivalence. Social Networks. 10: 313-341.

Kalish, Yuval and Garry, Robins (2006). Psychological predisposition and network structure: The relationship between individual predisposition, structural holes and network closure. Social Network. 28/1: 56-84.

Knoke, David and Song Yang (2008). Social Network Analysis. London: SAGE Publications.

Lane, B. Robert (1962). Patrilateral Cross-Cousin Marriage: Structural Analysis and Ethnographic Cases. Ethnology. 1/4: 467/499.

Linton, Ralph (1936). The Study of Man. New York: D. Appleton-Century 
Company.

Lorrain, F. and H. White (1971/2008). Structural equivalence in social networks. In: L. C. Freeman (ed), Social Network Analysis Volume 3. The Structure of Social Positions. London: SAGE Publications, pp. 3-38.

Mizruchi, S. Mark (1990). Cohezion, Structural Equivalence, and Similarity of Behavior: An Approach to the Study of Corporate Political Power. Sociological Theory. 8/1: 16-32.

Palloti, F. and A. Lomi (2011). Network influence and organizational performance: the effects of tie strength and structural equivalence. European Management Journal 29: 389-403.

Prell, Christina (2012). Social Network Analysis. London: SAGE Publications.

Sailer, L. Douglas (1978). Structural equivalence: meaning and definition, computation and application. Social Networks. 1: 73-90.

Veber, Maks (1976). Privreda i društvo. Beograd: Prosveta.

Walker, G., B. Kogut and W. Shan (1997). Social capital, structural holes and formation of industry network. Organization Science 8 (2): 109-125.

Wasserman, Stanley and Katherine Faust (1994). Social Network Analysis. Methods and Applications. Cambridge: University Press.

White, R. Douglas and Karl P. Reitz (1983). Graph and semigroup homomorphisms on networks of relations. Social Networks. 5: 193-234.

White, C. Harrison (1963). Anatomy of kinship. Mathematical Models for Structures of Cumulated Roles. Englewood Cliffs, NJ: Prentice-Hall.

White, C. Harrison, Scott, A. Boorman and Ronald L. Breiger (1976). Social Structure from Multiple Networks. I. Blockmodels of Roles and Positions. American Journal of Sociology. 81/4: 730-780.

Valentina Sokolovska

Aleksandar Tomašević

THE POSITION AND ROLE IN THE ANALYSIS OF SOCIAL NETWORKS 
The basic aim of the thessis is to introduce the model of structural equivalence and to point to its significance in the research of the positions and roles in the analysis of social networks. For this reason, the work stresses the problems that occur while defining positions and roles both in Sociology and in social networks theory. Afterwards, the authors presented a brief overview of the most important works in which the aforementioned method is developed. The authors emphasize the stringent demands, required by the structural equivalence as a condition for the performance and its restricted usage in the research process. Due to this, the individual alternative approaches used in the research of the positions and roles are being introduced.

Key words: position, role, structural equivalence method. 